Natural and Applied Sciences International Journal (NASIJ) eISSN: 2788-4619 (online)

https://doi.org/10.47264/idea.nasij/2.1.3

Vol. 2, No. 1, (January-December 2021), 26-38

https://www.ideapublishers.org/index.php/nasij

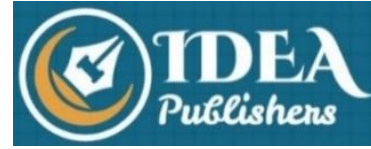

Research Article

\title{
Performance evaluation of Asphalt Rubber Gap-graded mixture
}

\author{
Akram Hazaa M. A. Alhelyani* | Zhang Shuwen \\ School of Civil Engineering, Zhengzhou University, China. \\ *Corresponding Author Email: akramhazaa1994@gmail.com
}

Published Online: November 24, 2021

\begin{abstract}
One of the most successful means of improving paving performance is by the use of Crump Rubber (CR). Increased demand for Asphalt Rubber Gap-graded (AR-Gap) mixtures as a pavement material has resulted from improvements in the basic asphalt binder as well as environmental advantages and improved performance in recent years. A number of agencies and researchers conducted AR-Gap mix studies to evaluate the design and performance of AR-Gap mixtures. In this study, the most recent research and practices in the design of AR-Gap mixtures were reviewed, and the performance characteristics of these mixtures were also summarized. In addition, the positive effect of adding ground rubber on the performance of the mixtures, including the effect on fatigue cracking, drainage, moisture susceptibility and permanent deformation is also reviewed. In conclusion, future aims in the building of AR-Gap pavement and performance potential were discussed, which will assist it in becoming a viable long-term pavement choice in the future. Based on the results of the evaluation process, it was discovered that there is still potential to improve the current design state of AR-Gap mixtures as well as the effect of rubber inserts in improving the performance of the mix.
\end{abstract}

Keywords: Asphalt Rubber, Crumb Rubber, AR-Gap mixtures, pavement material, flexible pavements, gap-graded gradation, gradation, mix design, asphalt binder.

\section{How to Cite:}

Alhelyani, A. H. M. A., \& Shuwen, Z. (2021). Performance evaluation of Asphalt Rubber Gap-graded mixture. Natural \& Applied Sciences International Journal (NASIJ), 2(1), 26-38. https://doi.org/10.47264/idea.nasij/2.1.3

\section{Publisher's Note:}

IDEA PUBLISHERS (IDEA Publications Group) stands neutral regarding jurisdictional claims in the published maps and institutional affiliations.

\section{Copyright:}

(C) 2021 The Author(s), published by IDEA PUBLISHERS (IDEA Publications Group)

\section{Licensing:}

This is an Open Access article published under the Creative Commons Attribution-NonCommercial 4.0 International License (http://creativecommons.org/licenses/by-nc/4.0/) 


\section{Introduction}

The most popular type of pavement is flexible asphalt (bituminous) highways, which are quite inexpensive. In a multi-layer system, the load-distribution features of the flexible pavement play a role in determining its overall performance. These pavement systems are subject to fatigue cracking, rutting, low-temperature cracking, stripping and raveling during the course of their service lives. Furthermore, the features of these pavements change with time, as does the effect of temperature on the asphalt binder, resulting in the behavior of the mixture being influenced by both time and temperature at the same time. In recent years, a number of readily available solutions have gained substantial traction in the reduction of the influence of asphalt binders time-temperature susceptibility, hence extending the life of these pavements. One of the most effective approaches is to add additives to the base asphalt binder. The most extensively utilized polymers for base binder modification are synthetic and natural polymers, such as Crumb Rubber (CR) (Venudharan et al., 2017).

CR is typically composed of $70 \%$ recoverable rubber, $15 \%$ steel, $3 \%$ fiber, and $12 \%$ extraneous material (Way et al., 2012). The pavement community has become interested primarily in modifying the basic asphalt binder using CR because of the material's numerous benefits including:

- Asphalt overlays have less reflective cracking,

- reduce maintenance expenditures,

- fatigue cracking and rutting resistance,

- longer lifespan of the pavement,

- lower levels of noise, and

- Scrap tires are used efficiently, which helps to keep the environment clean (Liu et al., 2012; Soares et al., 2021; Venudharan et al., 2017).

McDonald discovered using CR asphalt binders in the 1960s (Neto et al., 2003). Since then, CR has grown in popularity as a binding agent for Hot Mix Asphalt (HMA) applications. Various HMA gradations have been adjusted with CR and employed in the various layers of the flexible pavement system, and various gradations of aggregate have been employed in the production of Asphalt Rubber (AR) mixtures.

The addition of CR modifiers in a gap or open-graded gradation significantly improved their performance characteristics because these gradations give ample room inside the mix matrix for CR particles to agglomerate and hence, increase their performance characteristics. In contrast, due to the fact that standard dense-graded mixes lack sufficient voids to accommodate CR particles in the dense mix matrix, applying CR modifiers to them has either resulted in mediocre results or has resulted in a complete failure (Kaloush et al., 2012).

In addition, previous investigations show that gap-graded mixtures containing rubber as a modification have been applied successfully in the field whether it is the base layers, sub-base, binder, or surface layers. The design also asks for an increase in porosity due to the gap aggregate structure, which promotes proper drainage and as a result, reduces moisture problems. As a result, an asphalt pavement mixture made up of gap aggregate gradation with asphalt binder and rubber (often referred to as "Asphalt Rubber Gap-graded or AR-Gap") is deserving of further research in order to gain a better understanding of its overall performance. 
For existing design techniques to be developed to meet the different regional, traffic, and climatic conditions, a full discussion overview of currently available uses of chemical resistance modification in flexible pavement development and rehabilitation is required. Therefore, the primary purpose of this review study article was to compile and give the most up-to-date information on the concept, performance and advantages of AR-Gap mixtures, which have surpassed typical asphalt pavements in terms of durability and performance. An overview of the prospects for AR-Gap mixtures was presented in the conclusion of the study, illustrating their value as a superior pavement material for a variety of circumstances.

In this study, the most recent research and practices in the design of AR-Gap mixtures were reviewed, and the performance characteristics of these mixtures were also summarized. In addition to review the positive effect of adding ground rubber on the performance of the mixtures, including the effect on fatigue cracking, drainage, moisture susceptibility and permanent deformation. In conclusion an overview of the future prospects for AR-Gap mixtures was presented, illustrating their value as a superior pavement material for a variety of circumstances.

\section{Overview of Asphalt Rubber (AR)}

As the number of vehicles on the road grows, so does the number of tires. According to estimates, around the globe billions of tires are produced each year, the most of which will end up as waste tires (Chen et al., 2020; Liu et al., 2021). To keep up with the increased volume of traffic, asphalt concrete must evolve as well in order to improve the material's resistance to rutting and cracking and also increase its durability (Wiranata \& Malik, 2021). Thus, to meet these performance standards, many modifications have been applied to HMA combinations, with ground tire rubber being one of these alterations. Over 80 percent of waste tires generated each year in the United States are recycled or used in a variety of industries, including agriculture, structural engineering and the petroleum industry.

Ground Tire Rubber (GTR) or Crumb Rubber (CR), which has been utilized in the paving industry since the 1960s, is one way of recycling scrap tires. Since then, it has grown in popularity around the world as a solution to a severe waste management problem and an improvement in asphalt surface performance (Chang et al., 2020; Liu et al., 2021). No matter how much tire composition differs from one manufacturer to another and from one type of vehicle to another, the primary components of all tires are nearly identical. Minor variations in the amounts of natural and synthetic rubber used in CR modified binders, according to the manufacturer, have no effect on their overall performance. Steel and fiber must be removed from the tire's structure before it can be used as a binder modifier or mix addition. The steel is normally removed using magnets. Aspiration is also used to remove the fiber. To be combined with asphalt binder or asphalt mix, the residual tire rubber must be reduced in size.

AR mixture produced by using scrap tire rubber particles that have been mechanically sheared and uniformly combined with high-performance modified asphalt in place of some aggregate in the asphalt mixture is a revolutionary and a new type of paving material. When a basic asphalt binder is combined with a specific size CR in asphalt mixtures, the resultant mixtures have greater physical properties than basic bitumen binders and are on the verge of approaching the performance of polymer-modified bitumen binders in terms of performance. The higher rheological qualities of the modified bitumen binder have played a significant role in the improved performance of AR pavements. 
Modified bituminous materials can provide demonstrable benefits to roadway construction and rehabilitation sections, such as improved road performance and durability, reduced road noise, and cost savings over the life of the road (Freitas \& Inácio, 2009; Raimundo et al., 2010; Souliman \& Eifert, 2016). Furthermore, adding rubber to a virgin binder leads to improve the binder's resilience to asphalt pavement distresses by reducing its temperature susceptibility.

AR is defined as a mixture of paving-grade asphalt cement, ground recycled tire rubber and additional additives containing at least $15 \%$ rubber by weight of the total asphalt binder nearly $1-3 \%$ by weight of the asphalt mixtures (ASTM D6114-09, 2009). AR can be applied for various purposes in asphalt pavement construction, including structural layers and surface modifications, in the same way that unmodified binder is. Based on the fractions and availability of rubber diameters, as well as the needs of client's various Departments of Transportation (DOT) in the United States suggest CR gradations. The procedure for grinding the tire rubber is one of the most essential aspects that can have a big effect on the CR modified binder's performance. These techniques include the following:

- Ambient grinding: in this process, scrap tires are pulverized at or above room temperature to generate irregular shapes particles with a large surface area, which improves their contact with the asphalt binder.

- Cryogenic grinding: In this process, the hammer mill is used to break the rubber into fine pieces with a small surface area after it has been frozen to make it more brittle by liquid nitrogen (Neto et al., 2006). Image of rubber crumbs taken with an electron microscope at different magnifications (100, 500, and 2000 times magnification) shown in the Figure (Wang et al., 2019).

Figure 1: Rubber crumbs micrographs at three different magnification levels: (a) 100x, (b) 500x, and (c) 2000x

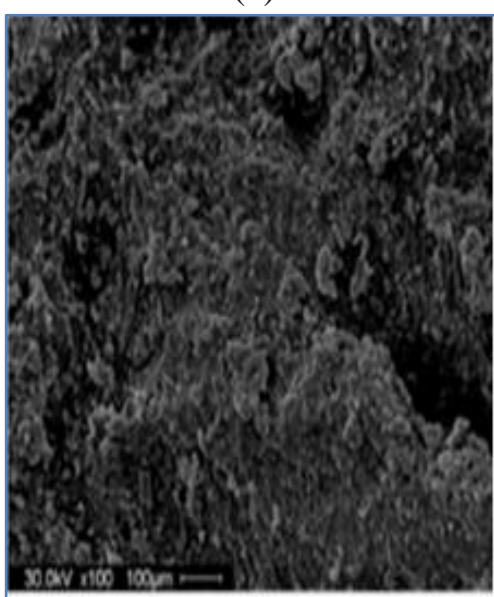

(a)

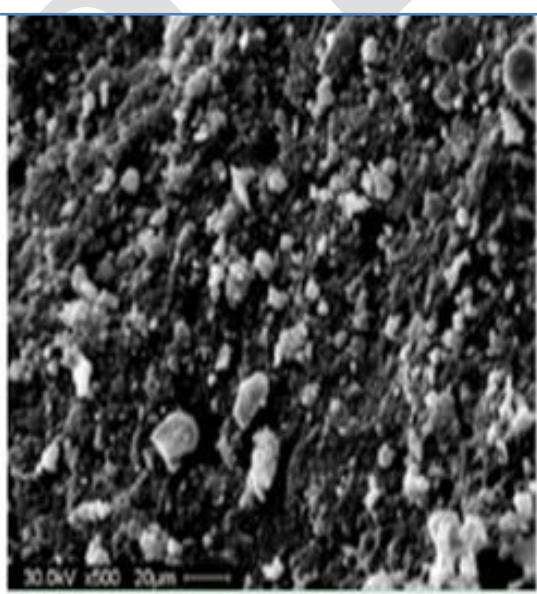

(b)

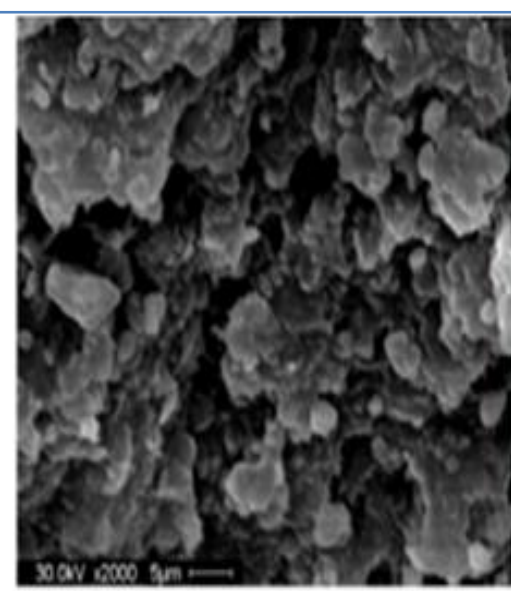

(c)

Furthermore, mixing ground tire rubber in asphalt pavements can be accomplished in two ways:

- A wet method: At high temperatures, the bitumen binder is replaced with rubber, the modified binder obtained is termed as "Asphalt Rubber". There are two main operating mechanisms in the wet process; (a) high viscosity wet method and (b) no agitation wet 
method. The distinctions between the two wet processes were summarized by Presti (2013).

- A dry method: The aggregates is blended with rubber in addition to the asphalt binder in a hot mix plant to partially replace one or more aggregate fractions; the modified binder obtained is termed as "rubberized asphalt". It is important to note that the performance of GTR-modified asphalt mixtures produced by each of these procedures varies. Understanding the differences between the two types of processes is critical for making the best decision on the type of process. In addition, each of these procedures must undergo the requisite testing and inspections to assure their success (March et al., 2016; Santagata et al., 2015; Shatnawi \& Long, 2000; Venudharan et al., 2017).

Several factors have been discovered to alter the Crumb Rubber Modified Binder (CRMB) during the production of a homogeneous combination of AR binder, including: (a) CR's interaction with different grades of virgin binders, (b) effect of mixing time on digestion; (c) Bitumen's impact on rubber morphogenesis; (d) CR degradation; (e) features of CR's wet kinetics and (f) impact of temperature and processing time on the CRMB (Venudharan et al., 2017).

The use of AR becoming more widespread will undoubtedly have a positive impact on the environment by reducing waste tire disposal and a potential benefit in terms of creating a better asphalt mixture. As a result, it's critical to compare the physical, technical, and performance characteristics of asphalt rubber combinations to those of conventional mixtures.

Figure 2. Techniques to produce Tire Rubber modified asphalt pavement

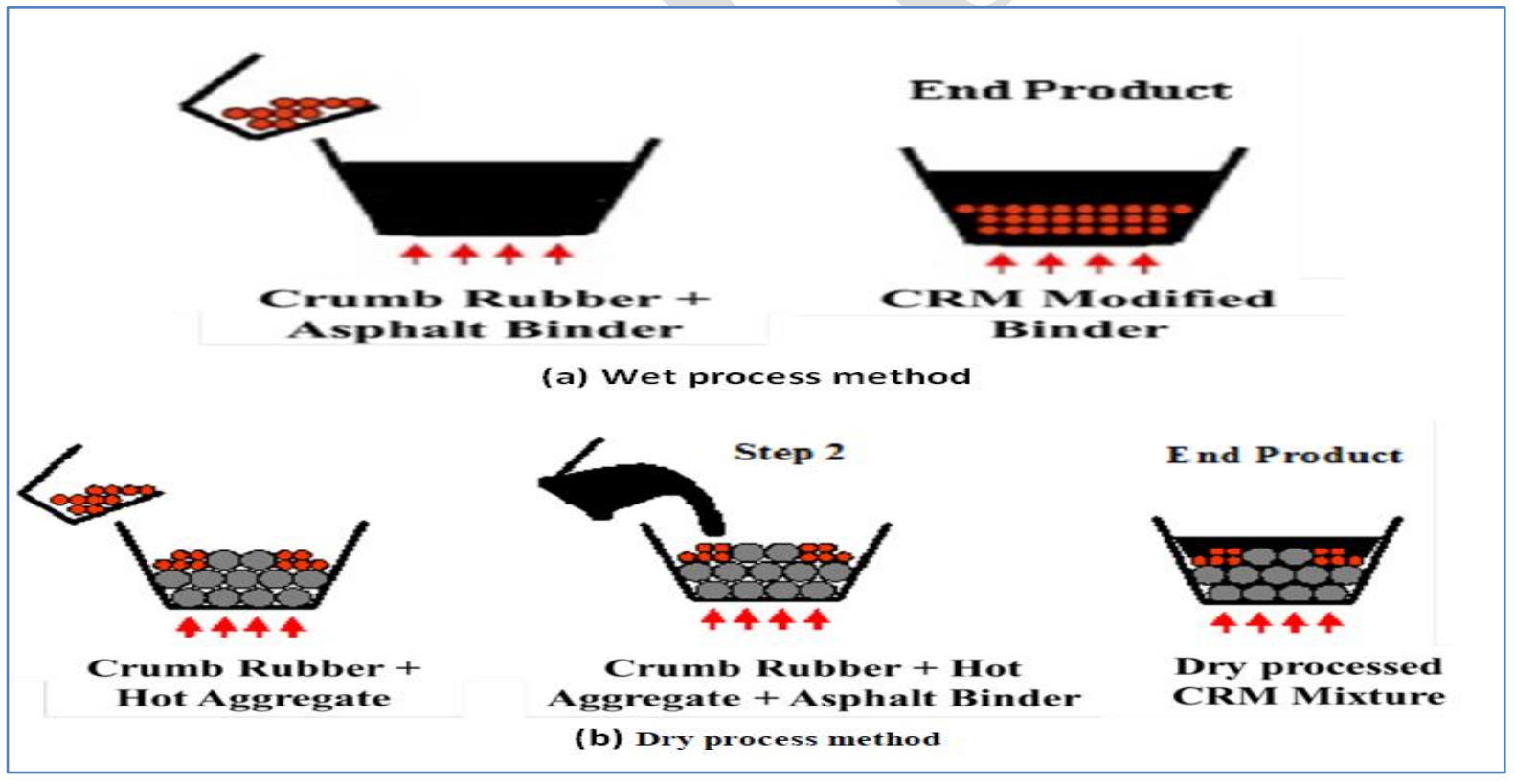

\section{Asphalt Rubber mixtures}

Because of high performance features, HMA mixtures was combined with AR binder and effectively used in various states of the United States to prevent reflection cracking in flexible pavement systems. AR mixes have since been popular in the United States, Portugal, Italy, South Africa, Brazil, Sweden, and China as a reflective cracking mitigation strategy (Venudharan et al., 2017). 
ARHMA mixtures came in a variety of gradations, including gap, dense and open graded, and to acquire a deeper knowledge of the increased performance of ARHMA mixtures and the effect of the aggregate skeleton on the mixture's properties, several research investigations were done. ARHMA mixtures have used successfully in different structure layers include wearing course, surface course and subbase course.

Researchers discovered that the performance for mixture that uses dense-graded gradation with rubber modification outperformed regular dense-graded gradation. Furthermore, AR successfully combined with an open-graded gradation primarily for the purpose of facilitating good functional performance, i.e., reducing noise, lowering emissions from tire wear and minimizing the effects of urban heat islands. According to the researchers, the gap-graded gradation with rubber-modified binder also produces a better mix with lower susceptibility for moisture and drainage, as well as higher rutting resistance.

\section{Mix design and performance evaluation}

Gap-graded gradation with rubber-modified binder leads to a better mix with reduced susceptibility for moisture and drainage, as well as higher rutting resistance. Grasp the performance behavior of asphalt mixtures requires a thorough understanding of mix design. Ideal binder content, aggregate gradation and volumetric of the compressed sample are all important criteria to consider while designing a mix. Several countries have established gapgraded gradation criteria due to the varying particular of the traffic and environmental conditions in the region. The AR-Gap mix design approach had to be established using laboratory performance evaluation and a database of in-field performance.

Performance evaluation of AR-Gap mixtures determines the thickness layers design, durability, as well as other structural and functional aspects. As a result, the mix's resistance to various distresses, such as fatigue cracking, drainage, water permeability and permanent deformation or rutting is all important factors to consider when evaluating pavement performance primarily for their structural qualities. Several researchers studied the AR-Gap mixes' performance characteristics which are summarized in the ensuing sections.

\subsection{Fatigue cracking}

Premature rutting and fatigue cracking under repeated stress as a result of mix design and construction flaws are common challenges that AR pavements face. Liu et al. (2021) evaluated fatigue resistance. In this study, it has been discovered that the best AR content may be achieved by analyzing the resistance to high temperature and fatigue of gap graded AR mixtures through the use of flow testing, Marshall stability testing, wheel tracking testing and fatigue testing. The fatigue test can be used to measure how resistant asphalt specimens are to cracking after being subjected to repetitive loads over a period of time. In accordance with specification T0715, it is a stress-controlled test performed on an American Materials Testing and Simulation Machine (MTS) in accordance with the specification. The following were the conditions under which the tests were conducted: When the test began, the temperature was set 15 degrees Celsius, the specimen measured 250 millimeters in length, 40 millimeters in width, and 40 millimeters in height, and the loading rate was 50 millimeters per second. From the results and analysis, study have found that Gap Graded Asphalt Rubber GGAR fatigue curves was smaller than that of Stone Matrix Asphalt (SMA), which means that GGAR exhibited lower fatigue sensitivity, which indicates that GGAR would have a longer fatigue life. 
Abojaradeh et al. (2010) studied typical cracking parameters for AR combinations used in Arizona and compared the performance of these AR mixtures to that of other standard asphalt mixtures. All test specimens in this study (gap and open graded mixtures) were made with hot mix AR combinations and tested at various temperatures, as stated in the draft indirect tensile test methodology produced for the revised 2002 design guide. The fatigue testing revealed that the AR combinations would have a longer fatigue life than traditional dense graded mixtures. The fracture energy data showed that the AR mixtures are less impacted by decrease in temperature than the standard mixes, making the AR mixtures more resistant to thermal cracking in the field.

Kaloush et al. (2009) studied the fatigue-cracking resistance of Swedish field gap mixtures to assess the material characteristics and performance parameters for graded mixtures with "Reference Gap" and "Asphalt Rubber Gap" graded aggregates that were used on the Swedish Malmo E-06 highway. In order to evaluate the fatigue performance of pavements, flexural fatigue testing has been implemented. A saw is used to cut the beams to the requisite specifications of $63.5 \mathrm{~mm}$ broad, $50.8 \mathrm{~mm}$ high and $381 \mathrm{~mm}$ long, which are obtained from compacted specimens. According to the results of the tests, the reference mix has a longer fatigue life than the AR mix when subjected to high strain values. The AR combination, on the other hand, offers a longer fatigue life at lower strains. Because the pavement sections are part of a roadway, the AR gap graded mixture's estimated fatigue life is higher than the reference mix because the strain levels are expected to be lower $(80 \mathrm{~km} / \mathrm{h}$ vehicle speed $)$.

Cheng et al. (2019) assessed the fatigue cracking of different mixtures from Arizona field sections as part of bigger Arizona DOT projects. When bending beam tests were done on the field mixtures, AR-Gap blends were found to have a longer fatigue life than dense-graded mixtures. Experiments also demonstrated that open-grade mixes with AR combinations have more fatigue cracking resistant than AR-Gap mixtures, possibly as a result of the combinations decreased initial stiffness. Mashaan et al. (2014) also looked at the effect of CRM on SMA stiffness and fatigue characteristics. In this situation as well, the research showed that CRreinforced SMA mixes had a longer fatigue life than SMA mixes without CR.

\subsection{Drain-down}

The binder's proclivity for draining off the aggregate and settling toward the bottom. is known as drain-down. Drain-down is more likely in gap-graded mixtures with a greater amount of asphalt binder levels. It's critical to examine the mix's resistance to drain-down since draindown causes inappropriate mixing and, as a result, changes the volumetrics. Several tests were conducted to assess the AR mixture's resistance to drain-down, and it was discovered that AR mixtures were resistant to drain-down.

According to the findings and analyses found from the drain down test that was established by the National Center for Asphalt Technology (NCAT) (2006) to investigate the efficacy of AR in preventing drainage in SMA mixtures, the drainage in SMA mixtures with AR was 0.011 percent, with a maximum permissible of 0.3 percent. Moreover, Taiwanese researchers Chiu and $\mathrm{Lu}$ (2007) investigated the AR-SMA drain down using asphalt binder that contain $20 \% \mathrm{CR}$ (mix design as per ADOT) and discovered that drainage was not an issue with this mixture.

In their study, Putman and Amirkhanian (2004) discovered that at $162^{\circ} \mathrm{C}$ and $177^{\circ} \mathrm{C} \mathrm{SMA}$ mixtures with AR had zero percent drain-down, which indicated that CR's action as a 
stabilizing agent increased the SMA mix's resistance to drain-down at these temperatures. In a related investigation, Fontes et al. (2006) discovered that Caltrans AR Gap Graded (ARGG) was similarly resistant to drainage. As a result of the discovery that ARGG with ambient and cold crumb rubber modifiers meets the drain down standards set by Caltrans, the maximum permitted binder drain-down threshold has been set to 4 grams.

\subsection{Moisture susceptibility}

Moisture susceptibility is one of the most common reasons for HMA pavement failure. Moisture infiltration into the mix reduces the adhesive bond between the asphalt and the aggregate, lowering the material's mechanical properties. HMA pavements are also prone to stripping and premature collapse due to the moisture susceptibility of asphalt mixes.

Mogawer et al. (2013) investigated the moisture resistance of AR-Gap contain warm mix with asphalt recycled pavement blends. They employed the Hamburg wheel-tracking system to determine the effect of adding AR to recycled asphalt pavement; from the results and analysis they discovered that all of the mixes met the moisture susceptibility standards according to the AASHTO 324 protocol.

To examine moisture susceptibility issues in SMA mixes, Chiu and Lu made SMA mixes with AR binders using 20 percent fine tire rubber and a maximum size of $0.600 \mathrm{~mm}$ sieve. According to TSR values, in terms of moisture susceptibility, SMA with AR formulations exhibit similar moisture sensitivity to standard SMA blends (Chiu \& Lu, 2007). In another study, Nadkarni et $a l$. investigated the moisture resistance of asphalt mixes using the dynamic modulus $\left|\mathrm{E}^{*}\right|$. The $\left|E^{*}\right|$ stiffness ratio value of ARAC with 9 percent asphalt content was found to be larger than 65 percent, indicating a lower possibility for moisture susceptibility (Nadkarni et al., 2009).

\subsection{Permanent deformation or rutting}

In a flexible pavement system, rutting is among the most typical types of failure, and it is linked to stresses and high temperatures. Rutting of AR-Gap mixtures has been the subject of various research studies, as these materials have proven to be effective in preventing irreversible deformation in the real world.

Kaloush et al. (2009) tested the rutting ability of Malmo E-06 highway field mixes purchased in Sweden. In this study the repeated load or flow number test was utilized to determine the rutting characteristics of asphalt pavements, a repeated dynamic load was applied for several thousand repetitions; the tests are carried out on cylindrical specimens with a diameter of 100 $\mathrm{mm}$ and a height of $150 \mathrm{~mm}$. A 0.1 -second have sine pulse load was used, with a 0.9 -second dwell (rest time). Both reference gap-graded and AR-Gap mixtures were subjected to repeated load tests using three replicate test specimens. According to the results the AR-Gap combinations had a greater flow number than the reference gap-graded mixtures, according to the data. As a result, the AR-Gap mixture should be less prone to irreversible deformation.

In a separate investigation, Chiu and $\mathrm{Lu}$ investigated the resistance to permanent deformation of AR-SMA blends using wheel tracking experiments at $60^{\circ} \mathrm{C}$. AR-SMA mixtures outperformed standard SMA mixtures in terms of rutting resistance because to the higher viscosity of the binder that modified with AR (Chiu \& Lu, 2007). 
Laboratorial set tests were used in Pais et al. (2015) study to determine the mechanical characteristics, fatigue and permanent deformation of Brazilian AR and asphalt mixtures, as well as compare them to conventional asphalt. According to the findings of this study, Brazilian AR mixes have high resistance to permanent deformation and a long fatigue life when it comes to mixture control. As a result, it can be stated that the application of AR improves the characteristics of asphalt mixtures.

Huang et al. also examined the resistance to permanent deformation of several Louisiana field mixtures. AR Gap-graded mixes showed more flow and lower Marshall Stability than densegraded blends controls. ITS and resilient modulus were also lower in gap-graded CRM mixes than in control mixtures. In addition, rutting performance characteristics determined using a repeated simple shear test revealed that gap-graded gradation with AR mixtures and continuous blend AR binder outperformed traditional dense-graded mixtures in terms of rutting (Huang et al., 2002).

Studies and research related to evaluating the performance of asphalt rubber mixtures are numerous and cannot be mentioned. Among these studies, for example, but not limited to what is summarized in the below table- 1 .

Table-1. Summary of research studies on performance evaluate of AR-Gap mix

\begin{tabular}{|c|c|c|c|}
\hline Authors & Year & Tests & Study Findings \\
\hline Raad et al. & 2001 & Bending beam test & ARHM-GG \& DGAC \\
\hline Huang et al. & 2002 & $\begin{array}{l}\text { Flow and indirect tensile resilient } \\
\text { modulus, Marshall stability }\end{array}$ & $\begin{array}{l}\text { Open, gap, dense modified with } \\
\text { AR \& SAMI }\end{array}$ \\
\hline Fontes et al. & 2006 & Drain down test & $\begin{array}{l}\text { Drainage of Caltrans specified } \\
\text { ARHM-GG }\end{array}$ \\
\hline Sousa et al. & 2006 & Marshall mix design & AR-GG mix design concepts \\
\hline Kaloush et al. & 2007 & Bending beam test & AR-Gap, AR-Open \& DGAC \\
\hline Punith et al. & 2012 & TSR & Moisture susceptibility \\
\hline $\begin{array}{l}\text { Minhajuddin et } \\
\text { al. }\end{array}$ & 2015 & SCB test & AR-Gap, AR-Open \& DGAC \\
\hline Santagata et al. & 2014 & wheel-tracking test and Flow number & AR-Gap \& DGAC \\
\hline Meena et al. & 2015 & Resilient modulus test & AR-Open, AR-Gap \& DGAC \\
\hline Lavasani et al. & 2015 & $\begin{array}{l}\text { Dynamic creep test and uniaxial } \\
\text { resilient modulus }\end{array}$ & $\begin{array}{l}\text { stone-to-stone aggregate } \\
\text { contact measurement }\end{array}$ \\
\hline
\end{tabular}

\section{The promising performance of AR-Gap pavement}

It is critical to understand the features of the AR-Gap material as well as the mix design requirements and regulations. In order to produce an effective AR-Gap pavement, because research into the material's many properties, as well as its mix design processes, is still in the early stages. Recently years AR-Gap mixtures have been widely employed as successful materials in various parts of the world because to their superior performance compared to traditional dense mixes. However, because the current mix design standards issued by multiple agencies are regional in scope, they may fail to work as intended under a variety of traffic and environmental conditions that are outside of the guidelines' geography. As a result, it's critical to increase the current state-of-the-art AR-Gap mix design criteria, which will eventually lead to the material's global adoption. 
Furthermore, despite the fact that numerous CR gradation standards exist, no one is regarded as the best method for developing a high-performance AR binder in the construction of a strong AR-Gap mixture. As a result, it's possible to test a variety of CR gradation sieves, either individually or in combination, to find the best AR binder for gap-graded gradation. This will help researchers better understand the role of rubber in the development of an AR-Gap combination, which is currently a work in progress.

\section{Conclusion}

- The AR modified mixtures outperformed the standard mixture significantly. The results of the research showed that AR blends have improved mechanical properties. This meant that when these materials were used in the surface layers of pavements, they extended the project's life.

- The results of laboratory asphalt testing can be utilized to anticipate the behavior of asphalt mixtures in field applications. Mechanical testing, such as fatigue and permanent deformation, should be utilized to evaluate the performance of the mixtures.

- The results and analysis of the design and performance of AR mixtures can demonstrate that, when compared to typical SMA, GGAR demonstrated equal high-temperature performance due to coarse aggregate stone-on-stone contact and the enhanced stiffness of the AR.

- Asphalt Rubber Gap-graded (AR-Gap) mixture offers superior fatigue resistance than normal SMA because the flexibility of the AR increased cohesiveness, and thicker coated asphalt layer included in the AR-Gap mix.

- As the modulus is softer at lower temperatures the AR-Gap mix would be more resistant to low-temperature cracking and would also be more resistant to permanent deformation because of stiffer modulus at higher temperatures.

- Even though using AR-Gap mixtures have been applied all over the world according to the mix design specifications currently provided by various agencies, they are only applicable to a specific region and are likely to underperform when subjected to different traffic and environmental conditions outside of the guideline topography. As a result, the many characteristics of the material, as well as its mix design procedures, are still under investigation.

- The AR mixes maintained their good performance as higher energy is necessary to fracture the specimen. Due to this relative insensitivity to temperature changes, the AR mixtures are better resistant to thermal cracking in the field.

\section{Limitations and recommendations}

AR-Gap mix may fail to work as intended because of the fact that no CR gradation standards exist, as well as because mix design processes and standards issued by multiple agencies are regional in scope and depend on a variety of traffic and environmental conditions.

It's critical to improve the understanding of material's properties, as well as increase the current state-of-the-art AR-Gap mix design criteria by conducting various laboratory tests for AR-Gap mixtures to obtain successful asphalt mixtures with high performance in field applications, which will eventually lead to the material's global adoption. 


\section{References}

Abojaradeh, M., Jrew, B., Ghragheer, F., Kaloush, K. E., \& Abojaradeh, D. (2010). Cracking characteristic of asphalt rubber mixtures. Jordan Journal of Civil Engineering, 4(3), 205-210.

https://zu.edu.jo/MainFile/Profile_Dr_UploadFile/Researcher/Files/ActivityFile_26 13 54_2.pdf

Chang, M., Zhang, Y., Pei, J., Zhang, J., Wang, M., \& Ha, F. (2020). Low-Temperature Rheological Properties and Microscopic Characterization of Asphalt Rubbers Containing Heterogeneous Crumb Rubbers. Materials, 13(18), 4120. https://doi.org/10.3390/ma13184120

Chen, S., Ge, D., Jin, D., Zhou, X., Liu, C., Lv, S., \& You, Z. (2020). Investigation of hot mixture asphalt with high ground tire rubber content. Journal of Cleaner Production, 277, 124037. https://doi.org/10.1016/j.jclepro.2020.124037

Cheng, X., Liu, Y., Ren, W., \& Huang, K. (2019). Performance evaluation of asphalt rubber mixture with additives. Materials, 12(8), 1200. https://doi.org/10.3390/ma12081200

Chiu, C.T., \& Lu, L.C. (2007). A laboratory study on stone matrix asphalt using ground tire rubber. Construction and Building Materials, 21(5), 1027-1033. https://doi.org/10.1016/j.conbuildmat.2006.02.005

Fontes, L. P., Pereira, P. A., Pais, J. C., \& Trichês, G. (2006). Improvement of the functional pavement quality with asphalt rubber mixtures. https://repositorium.sdum.uminho.pt/handle/1822/7343

Freitas, E. F., \& Inácio, O. (2009). Noise absorption of gap graded mixtures with rubberized asphalt. https://repositorium.sdum.uminho.pt/handle/1822/17272

Huang, B., Mohammad, L. N., Graves, P. S., \& Abadie, C. (2002). Louisiana experience with crumb rubber-modified hot-mix asphalt pavement. Transportation Research Record, 1789(1), 1-13. https://doi.org/10.3141\%2F1789-01

Kaloush, K., Biligiri, K., Nordgen, T., Zeiada, W., Rodezno, M., Souliman, M., Reed, J., \& Stempihar, J. (2012). Laboratory evaluation of asphalt-rubber gap graded mixtures constructed on Stockholm highway in Sweden. In Asphalt Rubber Conference, Munich, Germany. http://www.ra-foundation.org/wp-content/uploads/2013/02/036PAP_032.pdf

Kaloush, K. E., Nordgren, T., Biligiri, K. P., Zeiada, W. A., Rodezno, M. C., Souliman, M. I., \& Reed, J. (2009). Laboratory evaluation of Asphalt Rubber Gap-graded mixture in Sweden. In Asphalt Rubber Conference, Nanjing, China. https://www.consulpav.com/shop/?product=laboratory-evaluation-of-asphaltrubber-gap-graded-mixture-in-sweden

Kaloush, K. E., Zborowski, A., Biligiri, K., Rodezno, M., \& De Mello, L. (2007). Performance evaluation of asphalt rubber mixtures in Arizona-silver springs and badger springs projects. Final Report Submitted to Arizona Department of Transportation.

Lavasani, M., Namin, M. L., \& Fartash, H. (2015). Experimental investigation on mineral and organic fibers effect on resilient modulus and dynamic creep of stone matrix asphalt and continuous graded mixtures in three temperature levels. Construction and Building Materials, 95(1), 232-242. https://doi.org/10.1016/j.conbuildmat.2015.07.146

Liu, L., Liu, Z., \& Yang, C. (2021). Pretreatment of Crumb Rubber with a Silane Coupling Agent to Improve Asphalt Rubber Performance. Advances in Materials Science and Engineering, 2021, 1828145. https://doi.org/10.1155/2021/1828145 
Liu, Y., Han, S., Zhang, Z., \& Xu, O. (2012). Design and evaluation of gap-graded asphalt rubber mixtures. Materials \& Design, 35, 873-877. https://doi.org/10.1016/j.matdes.2011.08.047

March, F., Ghabchi, R., Zaman, M., \& Arshadi, P. (2016). Use of ground tire rubber (GTR) in asphalt pavements: Literature review and dot survey. School of Civil Engineering and Environmental Science (CEES), The University of Oklahoma Norman, Oklahoma

Mashaan, N. S., Karim, M. R., Abdel Aziz, M., Ibrahim, M. R., Katman, H. Y., \& Koting, S. (2014). Evaluation of fatigue life of CRM-reinforced SMA and its relationship to dynamic stiffness. The Scientific World Journal, 2014, 968075. https://doi.org/10.1155/2014/968075

Meena, P. K., Saha, G., \& Biligiri, K. P. (2016). Estimation of fatigue life using resilient moduli of asphalt mixtures. Journal of Testing and Evaluation, 44(1), 424-438. https://doi.org/10.1520/JTE20140373

Minhajuddin, M., Saha, G., \& Biligiri, K. P. (2016). Crack propagation parametric assessment of modified asphalt mixtures using linear elastic fracture mechanics approach. Journal of Testing and Evaluation, 44(1), 471-483. https://doi.org/10.1520/JTE20140510

Mogawer, W., Austerman, A., Mohammad, L., \& Kutay, M. E. (2013). Evaluation of high RAP-WMA asphalt rubber mixtures. Road Materials and Pavement Design, 14(sup2), 129-147. https://doi.org/10.1080/14680629.2013.812846

Nadkarni, A. A., Kaloush, K. E., Zeiada, W. A., \& Biligiri, K. P. (2009). Using dynamic modulus test to evaluate moisture susceptibility of asphalt mixtures. Transportation Research Record, 2127(1), 29-35. https://doi.org/10.3141\%2F2127-04

Neto, S. A. D., Farias, M. M. d., Pais, J. C., Pereira, P. A., \& Santos, L. P. (2003). Behavior of asphalt-rubber hot mixes obtained with high crumb rubber contents. https://repositorium.sdum.uminho.pt/handle/1822/17179

Neto, S. A. D., Farias, M. M. d., Pais, J. C., \& Pereira, P. A. (2006). Influence of crumb rubber gradation on asphalt-rubber properties. https://repositorium.sdum.uminho.pt/handle/1822/7340

Presti, D. L. (2013). Recycled tyre rubber modified bitumens for road asphalt mixtures: A literature review. Construction and Building Materials, 49, 863-881. https://doi.org/10.1016/j.conbuildmat.2013.09.007

Pais, J. C., Thives, L. P., Pereira, P. A., \& Trichês, G. (2015). Constructing better roads with asphalt rubber. https://repositorium.sdum.uminho.pt/handle/1822/46136

Punith, V. S., Xiao, F., \& Amirkhanian, S. N. (2012). Evaluation of moisture sensitivity of stone matrix asphalt mixtures using polymerised warm mix asphalt technologies. International Journal of Pavement Engineering, 13(2), 152-165. https://doi.org/10.1080/10298436.2011.643792

Putman, B. J., \& Amirkhanian, S. N. (2004). Utilization of waste fibers in stone matrix asphalt mixtures. Resources, conservation and recycling, 42(3), 265-274. https://doi.org/10.1016/j.resconrec.2004.04.005

Raad, L., Saboundjian, S., \& Minassian, G. (2001). Field aging effects on fatigue of asphalt concrete and asphalt-rubber concrete. Transportation Research Record, 1767(1), 126-134. https://doi.org/10.3141\%2F1767-16

Raimundo, I., Freitas, E. F., Inácio, O., \& Pereira, P. A. (2010). Sound absorption coefficient of wet gap graded asphalt mixtures. https://repositorium.sdum.uminho.pt/handle/1822/17264 
Soares, M. P., Cerqueira, N. A., Almeida, F. F. D., Azevedo, A. R., \& Marvila, M. T. (2021). Technical, Environmental, and Economic Advantages in the Use of Asphalt Rubber. In Characterization of Minerals, Metals, and Materials 2021 (pp. 577-586). Springer. https://link.springer.com/chapter/10.1007/978-3-030-65493-1_59

Santagata, E., Baglieri, O., Alam, M., Lanotte, M., \& Riviera, P. P. (2015). Evaluation of rutting resistance of rubberized gap-graded asphalt mixtures. Proceedings, $6^{\text {th }}$ International Conference Bituminous Mixtures and Pavements (pp. 407-412). https://www.researchgate.net/publication/278671472_Evaluation_of_rutting_resista nce_of_rubberized_gap-graded asphalt_mixtures

Shatnawi, S., \& Long, B. (2000). Performance of asphalt rubber as thin overlays. Proceedings of the Asphalt Rubber 2000 Conference. https://www.researchgate.net/publication/265844825_PERFORMANCE_OF_ASP HALT_RUBBER_AS_THIN_OVERLAYS

Souliman, M. I., \& Eifert, A. (2016). Mechanistic and economical characteristics of asphalt rubber mixtures. Advances in Civil Engineering, 2016, 8647801. https://doi.org/10.1155/2016/8647801

Venudharan, V., Biligiri, K. P., Sousa, J. B., \& Way, G. B. (2017). Asphalt-rubber gap-graded mixture design practices: a state-of-the-art research review and future perspective. Road Materials and Pavement Design, 18(3), 730-752. https://doi.org/10.1080/14680629.2016.1182060

Wang, X., Fan, Z., Li, L., Wang, H., \& Huang, M. (2019). Durability Evaluation Study for Crumb Rubber-Asphalt Pavement. Applied Sciences, 9(16), 3434. https://doi.org/10.3390/app9163434

Way, G. B., Kaloush, K., \& Biligiri, K. P. (2012). Asphalt-rubber standard practice guide-an overview. Proceedings of Asphalt Rubber, 23-40. http://www.ra-foundation.org/wpcontent/uploads/2013/02/001-PAP_012.pdf

Wiranata, A., \& Malik, A. (2021, October). The effect of technical natural rubber mastication with wet process mixing on the characteristics of Asphalt-Rubber Blend. In Journal of Physics: $\quad$ Conference Series, $2049 \quad$ (1), 012081. https://iopscience.iop.org/article/10.1088/1742-6596/2049/1/012081/meta 